\title{
Critical evaluation of the American Joint Commission on Cancer (AJCC) 8th edition staging system for patients with Hepatocellular Carcinoma (HCC): A Surveillance, Epidemiology, End Results (SEER) analysis
}

\author{
Sivesh K. Kamarajah BMed Sci ${ }^{1}$ (D) | Timothy L. Frankel MD ${ }^{2}$ | \\ Christopher Sonnenday MD, MHS ${ }^{2}$ | Clifford S. Cho MD, FACS ${ }^{2}$ | \\ Hari Nathan MD, PhD, FACS ${ }^{2}$
}

${ }^{1}$ College of Medical and Dental Sciences, University of Birmingham, Birmingham, United Kingdom

2 Department of Surgery, University of Michigan, Ann Arbor, Michigan

\section{Correspondence}

Hari Nathan, MD, PhD, FACS, Assistant Professor, Department of Surgery, University of Michigan, 2210 Taubman Health Care Center, 1500 E Medical Center Dr, SPC 5343, Ann Arbor, MI 48109-5343.

Email: drnathan@med.umich.edu

Funding information

Agency for Healthcare Research and Quality, Grant number: K08HS024763
Background: Recently, the American Joint Committee on Cancer (AJCC) released its 8th edition changes to the staging system for hepatocellular cancer (HCC). We sought to validate the 8th edition staging system and compare the performance to the 7th edition using a population-based data set.

Methods: Using the Surveillance, Epidemiology and End Results (SEER) database (1998-2013), patients undergoing resection or transplant for non-metastatic HCC were identified. Overall survival was estimated using the Kaplan-Meier method and compared using log-rank tests. Concordance indices (c-indices) were calculated from Cox proportional hazards models to evaluate discriminatory power.

Results: The study included 8918 patients resected $(63 \%)$ or transplanted $(37 \%)$ for HCC. Nodal staging was performed in $19 \%$, of whom $5 \%$ had positive nodes. The cindex for the AJCC 8th edition staging system was 0.60 , similar to that for the 7 th edition (0.59). Survival was better for solitary tumors $>2 \mathrm{~cm}$ with vascular invasion than for multifocal tumors $<5 \mathrm{~cm}$ (median not reached vs 57 months, $P<0.0001$ ), although the staging system groups these tumors together as T2. For multifocal tumors $\leq 5 \mathrm{~cm}$, those with vascular invasion had worse survival than those without (median 42 vs 50 months, $P<0.001$ ), although the staging system draws no such distinction.

Conclusion: The AJCC 8th edition staging system for HCC performs similarly to the 7th edition. Future revisions should consider substratification of early HCC, specifically by distinguishing solitary tumors $>2 \mathrm{~cm}$ from multifocal tumors $\leq 5 \mathrm{~cm}$, and by considering the prognostic impact of vascular invasion in multifocal tumors $\leq 5 \mathrm{~cm}$. Future studies should aim to validate these findings.

KEYWORDS

hepatocellular cancer, SEER, staging, surgery, survival 


\section{1 | INTRODUCTION}

Hepatocellular carcinoma (HCC) accounts for $90 \%$ of primary liver cancer and is the 6th most common malignancy in the United States (US). ${ }^{1,2}$ Its annual US incidence is expected to double by $2030 .^{1,3}$ In 2016, there were 39000 new cases of HCC and 27000 deaths. Even after potentially curative surgical extirpation, the 5 -year survival rates are only $30 \%$ and $60 \%$ for resection and transplant, respectively. ${ }^{4}$ Novel therapeutic strategies ought to be tested in clinical trials to further improve outcomes in this cohort of patients. A well-defined staging system which accurately discriminates prognosis is needed in order to accurately stratify patients for such studies.

Recently, the American Joint Committee on Cancer (AJCC) released the new 8th edition staging system (Table 1), which incorporates several changes to the T classifications from the previous 7th edition staging system (Table 2). ${ }^{5,6}$ Previously, early HCC were categorized as T1 (solitary tumor, any size, no vascular invasion) or T2 (solitary tumor, any size, with vascular invasion; or multifocal tumors, none $>5 \mathrm{~cm}$, with or without vascular invasion). The new staging system defines T1a tumors as solitary tumors $\leq 2 \mathrm{~cm}$ with or without vascular invasion. Solitary tumors $>2 \mathrm{~cm}$ without vascular invasion (previously T2), are now separately classified as T1b. Larger solitary tumors $>2 \mathrm{~cm}$ with vascular invasion as well as multifocal tumors, none $>5 \mathrm{~cm}$, continue to be classified as T2. Larger multifocal tumors $\geq 5 \mathrm{~cm}$ remain classified as T3 disease. Finally, major vascular invasion (previously T3b) now qualifies as T4 disease.

Although multiple changes have been made in the AJCC 8th edition staging system, their impact on the prognostic value of the staging system has yet to be evaluated. Hence, we sought to validate the 8th edition staging system for HCC using a population-based data set. In particular, we sought to whether the staging of early HCC is appropriate, specifically whether further subdivision of T2 tumors should be considered.

\section{2 | METHODS}

\section{1 | Data source and study cohort}

Prospectively collected data from the Surveillance, Epidemiology, and End Results (SEER) database maintained by the National Cancer Institute were used for analysis in this study. The SEER database has grown to include 21 cancer registries, representing $28 \%$ of the United States population. As compared to the general US population, the SEER population is slightly more urban and has a slightly higher percentage of foreign-born individuals. Available data included patient demographics (eg, age, gender, race), tumor data (histology, grade, stage), and treatment data (surgery, radiation). Some data elements (eg, AJCC staging, details of surgical therapy, tumor size, lymph node involvement) are consistently available only in more recent time periods.

Using SEER data from 1998 to 2013, we identified patients aged 18-99 years with surgically extirpated (via resection or transplant), histologically confirmed non-metastatic hepatocellular carcinoma (HCC). Only patients undergoing surgical extirpation (ie, resection and liver transplant) were included because staging variables are reliably ascertainable from pathological specimens. This enables a valid appraisal of the new staging system for HCC. International Classification of Disease 3rd edition (ICD-O3) were used to identify HCC using site codes $\mathrm{C} 220$. Histology codes were used to specifically identify patients with HCC (8170-8175). Other variants of HCC and non-specific histologies (eg, "neoplasm" or "carcinoma, NOS,") were excluded from the analysis. Likewise, cases with vague histology codes of "neoplasm" (8000-8003), "carcinoma, NOS" (8010-8013), and "carcinoma undifferentiated, NOS" (8120-8122) were excluded (NOS, not otherwise specified). The AJCC 7th and 8th edition staging systems were derived using data on tumor size, lymph node involvement, number of tumors and vascular invasion, all of which are provided by the SEER database. In this study, c-indices were not calculated for patients with N1 classification due to small numbers. Cases with missing data for these variables were excluded.

\section{2 | Statistical analysis}

Categorical variables were compared using the chi-squared test. Nonnormally distributed data were analyzed using the MannWhitney $U$ test. Overall survival was estimated using Kaplan-Meier survival curves and compared using the log-rank test. Overall survival was chosen because this is the survival metric used by the AJCC and avoids potential bias from attribution of cause of death. A concordance index (c-index) was calculated to evaluate the discriminatory power of each staging system. ${ }^{7}$ A value of 0.5 indicates chance alone is as predictive as the staging system, whereas a level of 1.0 signifies perfect concordance. A Cox proportional hazards model was used with $T$ classification coded as indicator variables to obtain hazard ratios (HR), and the concordance index was calculated from this Cox model. ${ }^{8} \mathrm{Cox}$ proportional hazards modeling was also used to assess differences in survival after resection vs transplant. A separate model adjusting for potential confounding variables including sex, age, and race was also assessed. Stratified analyses were also carried out to examine impact of the staging systems in patients undergoing resection and transplantation separately, and c-indices for these subgroups were separately evaluated. A P-value of $<0.05$ was considered to be statistically significant. Data analysis were performed using $R$ Foundation Statistical software (R 3.2.1) with TableOne, ggplot2, Hmisc, and survival packages (R Foundation for Statistical Computing, Vienna, Austria).

\section{3 | RESULTS}

\section{1 | Patient demographics and time trends}

This study cohort included 8918 patients who underwent surgery for HCC between 1998 and 2013. Clinicopathologic data for the entire cohort are presented in Supplemental Table S1. In this cohort, 5590 (63\%) of patients had a surgical resection, and 3328 (37\%) patients 
TABLE 1 AJCC 8th Edition Staging System for Hepatocellular carcinoma

\begin{tabular}{|c|c|c|c|c|c|}
\hline \multirow[b]{2}{*}{ T1a } & \multirow{2}{*}{$\begin{array}{l}\text { Primary tumor }(\mathrm{T}) \\
\text { Solitary tumor } \leq 2 \mathrm{~cm} \text { with/without vascular invasion }\end{array}$} & \multicolumn{2}{|c|}{ Regional lymph nodes (N) } & \multicolumn{2}{|c|}{ Distant metastases (M) } \\
\hline & & $\mathrm{Nx}$ & $\begin{array}{l}\text { Regional lymph nodes } \\
\text { cannot be assessed }\end{array}$ & MO & No distant metastasis \\
\hline T2 & $\begin{array}{l}\text { Solitary tumor }>2 \mathrm{~cm} \text { with vascular invasion } \\
\text { or multifocal tumors, none }>5 \mathrm{~cm}\end{array}$ & N1 & $\begin{array}{l}\text { Regional lymph node } \\
\text { metastasis }\end{array}$ & & \\
\hline T4 & $\begin{array}{l}\text { Single tumor or multifocal tumors of any size } \\
\text { involving a major branch of the portal } \\
\text { vein or hepatic vein or tumor(s) with } \\
\text { direct invasion of adjacent organs } \\
\text { other than the gallbladder or with } \\
\text { perforation of visceral peritoneum }\end{array}$ & & & & \\
\hline Stage IB & $\mathrm{T} 1 \mathrm{~b}$ & NO & MO & & \\
\hline Stage II & $\mathrm{T} 2$ & NO & MO & & \\
\hline Stage IIIA & T3 & NO & MO & & \\
\hline Stage IIIB & $\mathrm{T} 4$ & NO & MO & & \\
\hline Stage IVA & Any $\mathrm{T}$ & N1 & MO & & \\
\hline Stage IVB & Any $\mathrm{T}$ & Any $\mathrm{N}$ & M1 & & \\
\hline
\end{tabular}

received a liver transplant. Only 19\% (1540/8918) of patients in the entire cohort had lymph nodes examined. Among patients undergoing liver resection, the rate of lymph node examination was 14\% (772/ 5594), significantly lower than among those receiving a liver transplant $(26 \%, 870 / 3328, P<0.001)$. Of those with at least one 1 lymph node examined, the median number examined was 1 (interquartile range, IQR 1-2), and the incidence of positive lymph nodes was $5 \%$. In patients undergoing surgical resection, the incidence of positive lymph nodes was 9\% (68/702), higher than in patients receiving liver transplant for HCC (1\%, 12/852).

TABLE 2 AJCC 7th Edition Staging System for Hepatocellular carcinoma

\begin{tabular}{|c|c|c|c|c|c|}
\hline \multirow[b]{2}{*}{ T1 } & \multirow{2}{*}{$\begin{array}{l}\text { Primary tumor }(\mathrm{T}) \\
\text { Solitary tumor without vascular invasion }\end{array}$} & \multicolumn{2}{|c|}{ Regional lymph nodes (N) } & \multicolumn{2}{|c|}{ Distant metastases (M) } \\
\hline & & $\mathrm{Nx}$ & $\begin{array}{l}\text { Regional lymph nodes } \\
\text { cannot be assessed }\end{array}$ & MO & No distant metástasis \\
\hline T2 & $\begin{array}{l}\text { Solitary tumor with vascular invasion, or } \\
\text { multifocal tumors, none }>5 \mathrm{~cm}\end{array}$ & No & $\begin{array}{l}\text { No regional lymph } \\
\text { node metastasis }\end{array}$ & M1 & Distant metastasis \\
\hline T3a & Multifocal tumors at least one of which is $>5 \mathrm{~cm}$ & N1 & Regional lymph node metastasis & & \\
\hline T3b & $\begin{array}{l}\text { Single tumor or multifocal tumors of any size involving } \\
\text { a major branch of the portal vein or hepatic vein }\end{array}$ & & & & \\
\hline T4 & $\begin{array}{l}\text { Tumor with direct invasion of adjacent organs other } \\
\text { than the gallbladder or with perforation of the } \\
\text { visceral peritoneum }\end{array}$ & & & & \\
\hline \multicolumn{6}{|l|}{ Stage } \\
\hline Stage I & $\mathrm{T} 1$ & No & MO & & \\
\hline Stage II & T2 & No & MO & & \\
\hline Stage IIIA & T3a & No & MO & & \\
\hline Stage IIIB & T3b & NO & MO & & \\
\hline Stage IIIC & $\mathrm{T} 4$ & NO & MO & & \\
\hline Stage IVA & Any $\mathrm{T}$ & N1 & MO & & \\
\hline Stage IVB & Any $T$ & Any N & M1 & & \\
\hline
\end{tabular}



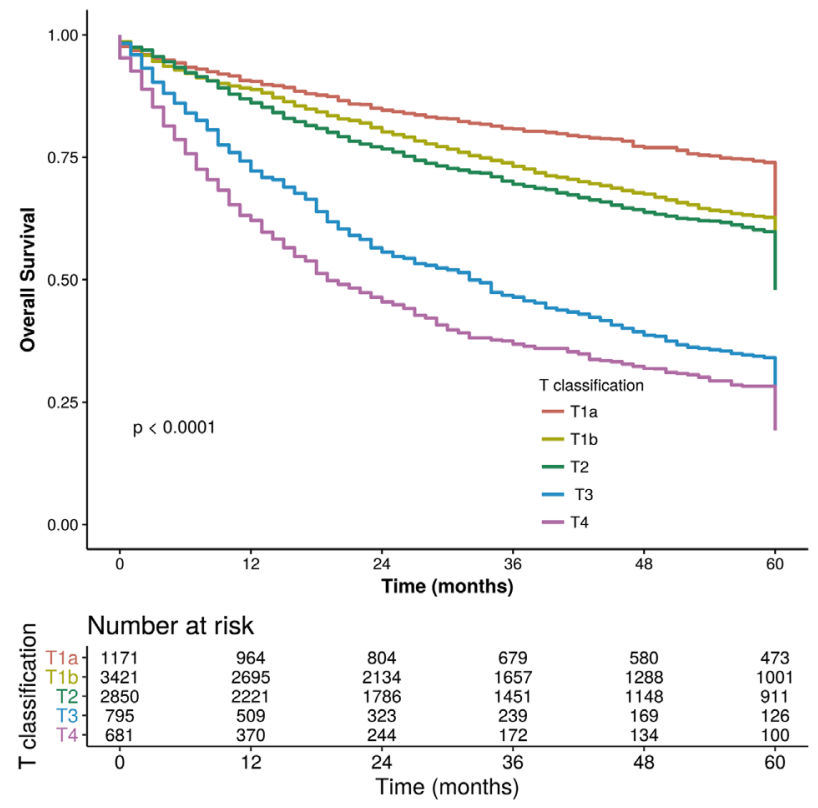

FIGURE 1 Overall survival of 8918 patients who underwent surgery for hepatocellular carcinoma stratified by AJCC 8th edition T classification

\section{2 | Overall survival by $\mathrm{T}$ classification}

As expected in the new AJCC 8th edition staging system, T1 tumors had the best prognosis (median survival 48 months, $\mathrm{Cl}_{95 \%}$ : 47-50 months), followed by $\mathrm{T} 2$ (45 months, $\mathrm{Cl}_{95 \%}$ : 44-46 months), T3 (33 months, $\mathrm{Cl}_{95 \%}$ : 32-35 months), and T4 tumors (28 months, $\mathrm{Cl}_{95 \%}$ : 27-30 months $\left.P<0.001\right)$. However, the difference in survival between $\mathrm{T} 1 \mathrm{a}$ and $\mathrm{T} 1 \mathrm{~b}$ tumors $\left(50, \mathrm{Cl}_{95 \%}\right.$ : 49-51 vs 47, $\mathrm{Cl}_{95 \%}$ : 46-48 months, $\left.P<0.001\right)$ was larger than that for $\mathrm{T} 1 \mathrm{~b}$ and T2 tumors (47 vs 45 months, $P=0.031$ ) (Figure 1). Cox regression for NO and Nx tumors demonstrated significant differences in survival between the new AJCC 8th edition T-classifications (Table 3). The corresponding $\mathrm{c}$-index for the 8th edition $\mathrm{T}$ classification was $0.60\left(\mathrm{Cl}_{95 \%}: 0.59-0.61\right)$, similar to that for the 7th edition (0.59, $\mathrm{Cl}_{95 \%}$ : 0.58-0.61).

We next performed analyses stratified by type of surgery (ie, resection vs transplant). Of the 7442 patients with early HCC (ie, T1 and T2 tumors), 3128 (42\%) received a liver transplant, and 4314 (58\%) patients underwent liver resection. As expected, there were significantly lower rates of liver transplant in patients with T3 and T4 tumors (14\%, 200/1476; $P<0.001$ ). Transplanted patients had superior survival across all stages, but monotonic trends in survival were observed in both groups. Specifically, median survival after resection was 47 months $\left(\mathrm{Cl}_{95 \%}\right.$ : 46-48) for $\mathrm{T} 1,39$ months $\left(\mathrm{Cl}_{95 \%}\right.$ : 38-40) for T2, 32 months $\left(\mathrm{Cl}_{95 \%}\right.$ : 30-34) for T3, and 27 months $\left(\mathrm{Cl}_{95 \%}\right.$ : 24-28) for T4 tumors. Median survival after transplant was 51 months $\left(\mathrm{Cl}_{95 \%}: 49-52\right)$ for $\mathrm{T} 1,51$ months $\left(\mathrm{Cl}_{95 \%}\right.$ : 50-52) for T2, 43 months $\left(\mathrm{Cl}_{95 \%}\right.$ : 38-46) for T3, and 43 months $\left(\mathrm{Cl}_{95 \%}\right.$ : 36-45) for T4 tumors. The corresponding c-indices were 0.62 ( $\left.\mathrm{Cl}_{95 \%}: 0.61-0.63\right)$ for resection and $0.61\left(\mathrm{Cl}_{95 \%}: 0.60-0.62\right)$ for transplant.

\section{3 | Outcomes of subgroups of T2 tumors}

In the AJCC 8th edition staging, T2 tumors include both solitary tumors $>2 \mathrm{~cm}$ with vascular invasion and multifocal tumors $\leq 5 \mathrm{~cm}$. There were 1381 patients with solitary tumors $>2 \mathrm{~cm}$ and vascular invasion, and 1373 patients with multifocal tumors $\leq 5 \mathrm{~cm}$. The 3 -year (70\% vs $54 \%$ ), 5 -year (45\% vs 32\%), and median (47, $\mathrm{Cl}_{95 \%}$ : $46-48$ vs $40, \mathrm{Cl}_{95 \%}$ : 39-42 months, all $P<0.001)$ survival were significantly longer for patients having solitary tumors $>2 \mathrm{~cm}$ with vascular invasion as compared to those with multifocal tumors $\leq 5 \mathrm{~cm}$. Analyses stratified by nodal status demonstrated similar survival trends favoring solitary tumors.

Among patients with T2 tumors, 1381 patients received a liver transplant. Pathologic staging exceeded the Milan criteria in 27\% (374/ 1381). The reason for exceeding Milan criteria was a solitary tumor $>5 \mathrm{~cm}$ in $1 \%(15 / 1381)$ and multifocal tumors $>3 \mathrm{~cm}$ in $26 \%$ (359/1381). Survival for solitary tumors $>2 \mathrm{~cm}$ was significantly longer than for multifocal tumors $\leq 5 \mathrm{~cm}$ in patients receiving a liver transplant, (median $52, \mathrm{Cl}_{95 \%}$ : $51-53$ vs 38, $\mathrm{Cl}_{95 \%}$ : 36-43 months, $P<0.001$ ) as well in those undergoing surgical resection (45, $\mathrm{Cl}_{95 \%}$ : 42-49 vs 39, $\mathrm{Cl}_{95 \%}: 38-41$ months, $P<0.001$, Figure 2 ).

\subsection{Impact of vascular invasion}

Our analysis confirmed that for T1 tumors, vascular invasion does not impact prognosis (median survival 50 vs 51 months, $P=0.5$, Supplemental Table S2). With regard to T2 tumors, the AJCC staging system considers the impact of (micro)vascular invasion in solitary tumors. However, it does not do so in multifocal tumors. As such, we analyzed the potential impact of vascular invasion in multifocal tumors $\leq 5 \mathrm{~cm}$. In this sub-group $(n=1106)$, there were $184(17 \%)$ patients with and 922 (83\%) patients without vascular invasion. In patients with multifocal tumors $\leq 5 \mathrm{~cm}$, the median survival with vascular invasion was significantly shorter than in the absence of vascular invasion (42, $\mathrm{Cl}_{95 \%}$ : $38-45$ vs $50, \mathrm{Cl}_{95 \%}$ : $48-51$ months; $\left.P<0.001\right)$. When stratified by nodal classification, patients with vascular invasion had shorter survival than patients without vascular invasion in both the NO and Nx groups.

Further analyses stratified by type of surgery demonstrated that vascular invasion remains a prognostic factor for overall survival in both groups (Figure 3). In patients undergoing surgical resection $(n=383)$, median survival with vascular invasion was significantly shorter than in the absence of vascular invasion (33, $\mathrm{Cl}_{95 \%}$ : $27-39$ vs 42, $\mathrm{Cl}_{95 \%}$ : 40-45 months; $P=0.003$ ). For patients undergoing liver transplant $(n=723)$, median survival with vascular invasion was significantly shorter than in the absence of vascular invasion (48, $\mathrm{Cl}_{95 \%}$ : 44-52 vs 53, $\mathrm{Cl}_{95 \%}$ : 52-54 months; $P=0.008$ ).

\subsection{Impact of tumor size in multifocal tumors}

We also evaluated the impact of tumor size on multifocal tumors using a cut-off of $5 \mathrm{~cm}$, as does the AJCC 8th edition staging system. In this analysis, $69 \%(1750 / 2536)$ of patients had multifocal tumors $\leq 5 \mathrm{~cm}$ and the remaining $31 \%(786 / 2536)$ had multifocal tumors $>5 \mathrm{~cm}$. Survival was significantly longer among patients with multifocal 
TABLE 3 Impact of T and N classification on survival in AJCC 8th edition staging system, stratified by $\mathrm{N}$ classification for the entire cohort

\begin{tabular}{|c|c|c|c|c|c|c|}
\hline & \multicolumn{2}{|l|}{ All patients } & \multicolumn{2}{|l|}{ No } & \multicolumn{2}{|l|}{$\mathrm{Nx}$} \\
\hline T1a & REF & & REF & & REF & \\
\hline $\mathrm{T} 1 \mathrm{~b}$ & $1.48(1.30-1.68)$ & & $1.21(0.90-1.60)$ & & $1.52(1.32-1.76)$ & \\
\hline T2 & $1.61(1.41-1.83)$ & & $1.20(0.90-1.56)$ & & $1.71(1.48-1.98)$ & \\
\hline T3 & $3.20(2.75-3.72)$ & $<0.001$ & $2.81(2.02-3.92)$ & $<0.001$ & $3.25(2.74-3.85)$ & $<0.001$ \\
\hline c-index & $0.60(0.59-0.61)$ & & $0.60(0.57-0.63)$ & & $0.60(0.59-0.62)$ & \\
\hline
\end{tabular}

tumors $\leq 5 \mathrm{~cm}$ as compared to those with multifocal tumors $>5 \mathrm{~cm}$ (48, $\mathrm{Cl}_{95 \%}$ : 47-49 vs $34, \mathrm{Cl}_{95 \%}$ : 32-35 months, $\left.P<0.001\right)$. When stratified by surgical management, patients with tumors $\leq 5 \mathrm{~cm}$ had a significantly longer survival than tumors $>5 \mathrm{~cm}$ after both resection (38, $\mathrm{Cl}_{95 \%}$ : $36-40$ vs $32, \mathrm{Cl}_{95 \%}$ : $30-34$ months, $\left.P<0.001\right)$ and liver transplant (51, $\mathrm{Cl}_{95 \%}: 50-53$ vs $42, \mathrm{Cl}_{95 \%}: 38-46$ months, $\left.P<0.001\right)$.

\section{4 | DISCUSSION}

Using a nationally representative dataset, this study empirically demonstrates that the new AJCC 8th edition T classifications result in comparable discrimination to that provided by the 7 th edition staging system, even when stratified according to resection or liver transplant. Its main improvement is in shifting the focus of substratification to earlier HCC, which are more common and more

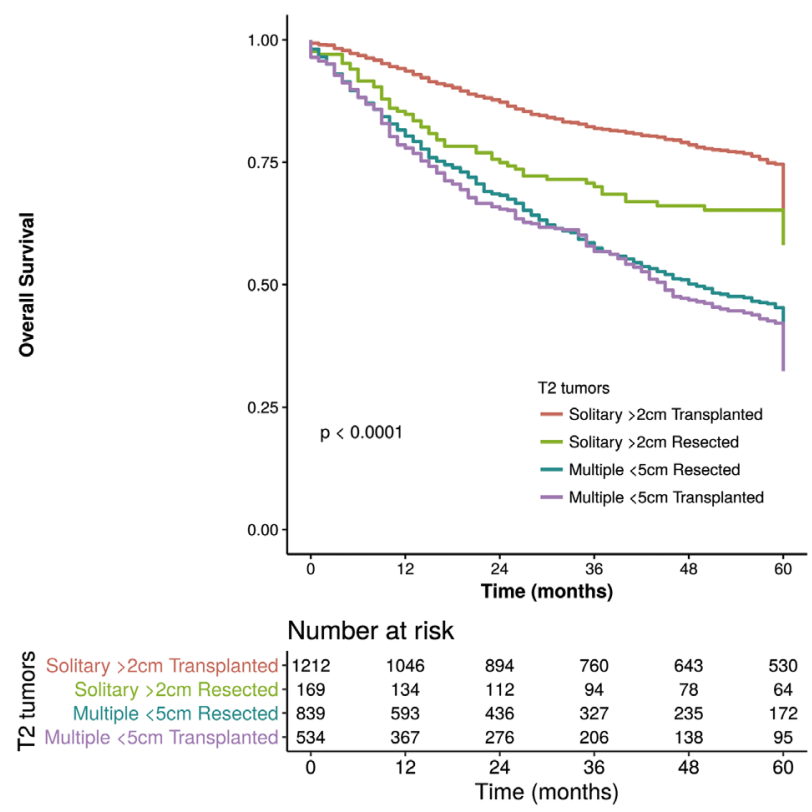

FIGURE 2 Overall survival of 2754 patients who underwent surgery for AJCC 8th edition T2 classification hepatocellular carcinoma stratified by type of surgery (resection vs transplantation) and number of tumors (solitary vs multifocal) likely to benefit from aggressive new therapies. The system generally performs as expected, with appropriate gradation of survival by $\mathrm{T}$ classification. However, it overlooks several key prognostic elements. For example, significant differences in survival exist between the subgroups categorized together as T2 tumors. Furthermore, vascular information continues to have prognostic importance in the setting of multifocal tumors. As such, we suggest that these groups should be distinguished in future revisions so as to continue the shift towards substratifying earlier HCC. ${ }^{9-11}$

In this study, survival for solitary tumors $>2 \mathrm{~cm}$ with vascular invasion was significantly longer than for multifocal tumors $\leq 5 \mathrm{~cm}$. This finding contrasts with those from a multi-center study by Shindoh et al, which reported that survival for solitary $\mathrm{HCC}>2 \mathrm{~cm}$ with microvascular invasion (median 55 months) was similar to that for multifocal HCC $\leq 5 \mathrm{~cm}$ (median 56 months, $P=0.5$ ) in patients undergoing surgical resection for HCC. The Shindoh report in part informed the revision of
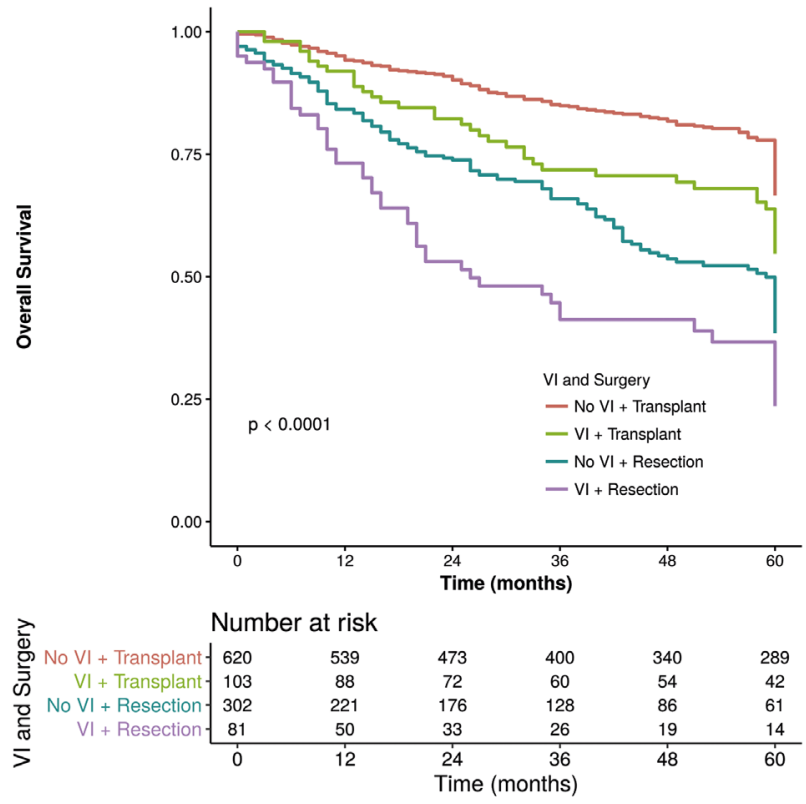

FIGURE 3 Overall survival of 1106 patients who underwent surgery for AJCC 8th edition T2 classification hepatocellular carcinoma with multifocal tumors $\leq 5 \mathrm{~cm}$ stratified by type of surgery (resection vs transplantation) and presence of microvascular invasion 
the T2 classification for the AJCC 8th edition staging system. ${ }^{12}$ However, this study may have been underpowered, as there were relatively few patients with solitary $\mathrm{HCC}>2 \mathrm{~cm}$ with microvascular invasion ( $n=334)$ and multifocal tumors $\leq 5 \mathrm{~cm}(n=80)$. In our study, there were significant differences in survival between these two subgroups, both in the liver resection and transplant groups. Hence, substratifying the T2 group further to differentiate solitary and multifocal tumors is warranted.

Our analyses also demonstrate that microvascular invasion confers an adverse prognosis in multifocal T2 tumors. However, the current AJCC staging system does not take this into account. Microvascular invasion has been associated with adverse prognosis in most studies. ${ }^{13-16} \mathrm{~A}$ recent meta-analysis of pooled studies demonstrated that microvascular invasion has prognostic value following resection and transplantation and is closely associated with increasing tumor size and multifocal disease. ${ }^{17}$ However, none of these previous studies specifically evaluated the impact of vascular invasion in multifocal tumors. In this analysis, median survival among patients with multifocal T2 tumors was reduced from 50 to 42 months with vascular invasion, suggesting that this prognostic factor should be considered in further stratifying multifocal tumors $\leq 5 \mathrm{~cm}$.

Limitations of this study include the lack of information on resection margin status, underlying etiology and severity of cirrhosis (if any), and viral hepatitis status. However, these are not variables that have been historically included in the HCC staging system, even though they may have some prognostic impact. Data on salvage therapies, such as transarterial chemoembolization (TACE), radioembolization, ablative therapies, and transplant as a second-line therapy, are also not reported. This is because staging variables are ascertainable on pathological specimens, hence allowing a valid appraisal of the staging system. Finally, there was no centralized pathologic review of tumor specimens in this cancer registry-based study. Despite this, previous studies have reported good agreement between the histologic subtypes of cancer reported by SEER and those assigned by independent reviewers. ${ }^{18}$ Notable strengths of our study include the large population included and the robust longterm follow-up of survival provided by SEER.

\section{5 | CONCLUSION}

In summary, the new AJCC 8th edition staging system with its revised T classification is valid in stratifying HCC patients undergoing surgical extirpation performs comparably to the AJCC 7th edition staging system. Stratified analyses by resection and liver transplant have similar performance under the new AJCC staging system. However, further stratification of T2 tumors may be required. Solitary tumors with vascular invasion demonstrated a superior prognosis as compared to multifocal tumors $\leq 5 \mathrm{~cm}$, suggested that distinction between this groups may be warranted, but these findings would need to be validated in future studies. Furthermore, vascular invasion is an important prognostic factor not only in solitary tumors, but also in multifocal tumors, and it should be incorporated as such into the staging system. Substratification of early HCC tumors may better allow clinicians to develop new and refined treatment strategies to improve outcomes of patients.

\section{CONFLICT OF INTEREST}

None declared.

\section{ORCID}

Sivesh K. Kamarajah iD http://orcid.org/0000-0002-2748-0011

\section{REFERENCES}

1. Petrick JL, Kelly SP, Altekruse SF, McGlynn KA, Rosenberg PS. Future of Hepatocellular Carcinoma Incidence in the United States Forecast Through 2030. J Clin Oncol. 2016;34:1787-1794.

2. Altekruse SF, McGlynn KA, Reichman ME. Hepatocellular carcinoma incidence, mortality, and survival trends in the United States from1975 to 2005. J Clin Oncol. 2009;27:1485-1491.

3. Altekruse SF, Devesa SS, Dickie LA, McGlynn KA, Kleiner DE. Histological classification of liver and intrahepatic bile duct cancers in SEER registries. J Registry Manag. 2011;38:201-205.

4. Yao FY, Fidelman N. Reassessing the boundaries of liver transplantation for hepatocellular carcinoma: where do we stand with tumor down-staging? Hepatology. 2016;63:1014-1025.

5. Amin MB, Greene FL, Edge SB, et al. The Eighth Edition AJCC Cancer Staging Manual: continuing to build a bridge from a population-based to a more "personalized" approach to cancer staging. CA Cancer J Clin. 2017;67:93-99.

6. Edge SB, Compton CC. The American Joint Committee on Cancer: the 7th edition of the AJCC cancer staging manual and the future of TNM. Ann Surg Oncol. 2010;17:1471-1474.

7. Royston P, Altman DG. External validation of a Cox prognostic model: principles and methods. BMC Med Res Methodol. 2013;13:33.

8. Harrell FE, Jr., Lee KL, Califf RM, Pryor DB, Rosati RA. Regression modelling strategies for improved prognostic prediction. Statistics in medicine. 1984;3:143-152.

9. El-Serag HB, Marrero JA, Rudolph L, Reddy KR. Diagnosis and treatment of hepatocellular carcinoma. Gastroenterology. 2008;134:1752-1763.

10. Nathan H, Hyder O, Mayo SC, et al. Surgical therapy for early hepatocellular carcinoma in the modern era: a 10-year SEER-medicare analysis. Ann Surg. 2013;258:1022-1027.

11. Tsuchiya N, Sawada Y, Endo I, Saito K, Uemura Y, Nakatsura T. Biomarkers for the early diagnosis of hepatocellular carcinoma. World J Gastroenterol. 2015;21:10573-10583.

12. Shindoh J, Andreou A, Aloia TA, et al. Microvascular invasion does not predict long-Term survival in hepatocellular carcinoma up to $2 \mathrm{~cm}$ : reappraisal of the staging system for solitary tumors. Ann Surg Oncol. 2013;20.

13. Sumie $\mathrm{S}$, Nakashima $\mathrm{O}$, Okuda $\mathrm{K}$, et al. The significance of classifying microvascular invasion in patients with hepatocellular carcinoma. Ann Surg Oncol. 2014;21:1002-1009.

14. Bertuzzo VR, Cescon M, Ravaioli M, et al. Analysis of factors affecting recurrence of hepatocellular carcinoma after liver transplantation with a special focus on inflammation markers. Transplantation. 2011;91: 1279-1285.

15. Mazzaferro V, Llovet JM, Miceli R, et al. Predicting survival after liver transplantation in patients with hepatocellular carcinoma beyond the Milan criteria: a retrospective, exploratory analysis. Lancet Oncol. 2009;10:35-43.

16. Wang CC, lyer SG, Low JK, et al. Perioperative factors affecting longterm outcomes of 473 consecutive patients undergoing hepatectomy for hepatocellular carcinoma. Ann Surg Oncol. 2009;16:1832-1842. 
17. Rodriguez-Peralvarez M, Luong TV, Andreana L, Meyer T, Dhillon AP, Burroughs AK. A systematic review of microvascular invasion in hepatocellular carcinoma: diagnostic and prognostic variability. Ann Surg Oncol. 2013;20:325-339.

18. Field RW, Smith BJ, Platz CE, et al. Lung cancer histologic type in the surveillance, epidemiology, and end results registry versus independent review. J Natl Cancer Inst. 2004;96:1105-1107.

\section{SUPPORTING INFORMATION}

Additional Supporting Information may be found online in the supporting information tab for this article.
How to cite this article: Kamarajah SK, Frankel TL,

Sonnenday C, Cho CS, Nathan H. Critical evaluation of the American Joint Commission on Cancer (AJCC) 8th edition staging system for patients with Hepatocellular Carcinoma (HCC): A Surveillance, Epidemiology, End Results (SEER) analysis. J Surg Oncol. 2018;117:644-650.

https://doi.org/10.1002/jso.24908 